\title{
ĐIỀU TRI THIẾU MÁU CHI CẤP TÍNH BẰG THUỐC TIÊU SỢI HUYẾT ĐỘNG MẠCH TRỰC TIẾP QUA ỐNG THÔNG
}

Lâm Văn Nút ${ }^{*}$, Lê Đức Tín ${ }^{*}$, Trịnh Vũ Nghĩa ${ }^{*}$ Đặng Thị Mỹ Hạnh ${ }^{*}$, Luu Thị Ánh Tuyết*

\section{TÓM TẮT}

Bệnh nhân được sử dụng thuốc tiêu sợi huyết (urokinase) trực tiếp qua ống thông điều trị tắc động mạch đùi nông và động mạch khoeo cấp tính, trong đó có 01 trường hợp can thiệp nội mạch đặt stent động mạch đùi nông kết hợp. Sau 24 giờ rút ống thông với kết quả chi bệnh nhân ấm, vận động cảm giác bình thường, siêu âm Doppler và chụp MSCT ghi nhận động mạch tái thông tốt, không trường hợp nào biến chứng. Điều trị bệnh thiếu máu chi cấp tính(ALI) bằng thuốc tiêu sợi huyết trực tiếp qua ống thông là phương pháp điều trị an toàn, hiệu quả và ít biến chứng.

Từ khóa: Thiếu máu chi cấp tính, thuốc tiêu sơi huyết.

\section{SUMMARY}

\section{TREATMENT WITH ACUTE LIMB}

\section{ISCHEMIA (ALI) BY INTERVENTION} COMBINATED THROMBOLYSIS DRUGS DIRECTED IN THE CATHETER

Patients were used urokinase drugs directly through a catheter for acute femoral and popliteal arteries occlusion, combined with stent in one case. After a 24-hour removal of the catheter, the patient had warm feet, the motion and sensation were recovery, ultrasound and MSCT scan had in revascularization, none of the complications. Intervention combined thrombolysis drug for the treatment of Acute Limb Ischemia (ALI) is safely, effectively and less complications.

Key words: Acute Limb Ischemia, Thrombolysis drugs.

\section{I. ĐẶT VẤN ĐỀ}

Thiếu máu chi cấp tính là một biến chứng mạch máu nặng thường gặp trong can thiệp mạch máu ngoại biên, tần xuất khoảng $10-16 \%$ và thường gây hậu quả nghiêm trọng như mất chi (lên đến $30 \%$ ) hay tử vong (15\%) nếu không được xử trí kịp thời và hiệu quả.

Nguyên nhân: Có 2 nguyên nhân chính do huyết khối tại chỗ hay huyết khối từ nơi khác đến. Nguyên nhân thứ nhất thường gặp hơn có thể do xơ vữa mạch máu, tắc cầu nối động mạch chi, tăng đông, chấn thương, viêm mạch máu, phình mạch. Nguyên nhân thứ hai có thể do các bệnh lý tim mạch và loạn nhịp, trong đó nguyên nhân rung nhĩ là thường gặp nhất, kế đến là bệnh van tim hậu thấp và nhồi máu cơ tim có huyết khối thất trái [1].

Ở nước ta hiện nay có hai phương pháp điều trị đối với thiếu máu cục bộ chi cấp tính là phẫu thuật hoặc can thiệp nội mạch. Trong công trình nghiên cứu này, chúng tôi nhận thấy rằng can thiệp nội mạch kết hợp điều trị thuốc tiêu sợi huyết động mạch trực tiếp qua ống thông là phương pháp điều trị ít xâm lấn nên hiệu quả và ít biến chứng, đặc biệt vai trò thuốc tiêu sợi huyết trong điều trị bệnh lý tắc động mạch chi cấp tính [2]. Do đó chúng tôi thực hiện công trình nghiên cứu nhằm đánh giá phương pháp điều trị quan trọng này.

II. Định nghĩa và phân loại thiếu máu cục bộ chi cấp (ALI - Acute Limb Ischemia) [2]

ALI là tình trạng giảm tưới máu chi đe dọa sự vận động và sống còn của chi xảy ra trước 14 ngày. Mức độ tổn thương tùy thuộc vào vị trí, mức độ tắc nghẽn lòng mạch và có hay không có tuần hoàn bàng hệ.

* Khoa Phẫu Mạch máu, BV Chọ Rẫy TPHCM Nguò̀i chịu trách nhiệm khoa học: TS. Lâm Văn Nút Ngày nhận bài: 01/05/2018 - Ngày Cho Phép Đăng: 20/05/2018

Phản Biện Khoa học: GS.TS. Bùi Đức Phú PGS.TS. Đặng Ngọc Hùng 
Hiệp hội can thiệp X-quang Châu âu đã đưa ra bảng phân loại mức độ nặng của ALI nhằm có chiến lược điều trị hợp lý và kịp thời [2]:

- Chi còn sống (limb viable): không có tiến triển nặng thêm của thiếu máu cục bộ chi.

- Đe dọa sự sống còn của chi (threatened): nếu tưới máu không được phục hồi nhanh.
3 dấu hiệu giúp phân biệt chi bị đe dọa với chi còn sống là: đau lúc nghỉ, mất cảm giác hay yếu cơ.

- Không hồi phục (irreversible): mất mô nặng hay tổn thương thần kinh vĩnh viê̂n.

Bảng 1. Phân loại của ALI

\begin{tabular}{|c|c|c|c|c|c|}
\hline & & \multicolumn{2}{|c|}{ Dấu hiệu lâm sàng } & \multicolumn{2}{|c|}{ Dấu hiệu Doppler } \\
\hline Phân loại & Mô tả & Mất cảm giác & Yếu cơ & Động mạch & Tĩnh mạch \\
\hline $\begin{array}{l}\text { I. Còn sống } \\
\text { II.Đe dọa } \\
\text { a.Mức độ nhẹ } \\
\text { b.Mức độ nặng } \\
\text { III.Không hồi phục* }\end{array}$ & $\begin{array}{l}\text { Không đe dọa ngay } \\
\text { Có thể cứu được nếu } \\
\text { điều trị ngay } \\
\text { Có thế cứu được nếu } \\
\text { tái thông ngay } \\
\text { Mất mô nặng hoặc } \\
\text { tồn thương thần kinh } \\
\text { vĩnh viễn không hồi } \\
\text { phuc }\end{array}$ & $\begin{array}{l}\text { Không } \\
\text { Nhẹ (đầu ngón) } \\
\text { hoặc không } \\
\text { Nhiều hơn ngón } \\
\text { chân và kèm với } \\
\text { đau lúc nghỉ } \\
\text { Nặng, không có } \\
\text { cám giác }\end{array}$ & $\begin{array}{l}\text { Không } \\
\text { Không } \\
\text { Nhẹ, trung bình } \\
\text { Nặng, liệt chi }\end{array}$ & $\begin{array}{l}\text { Có } \\
\text { Thường không có } \\
\text { Thường không có } \\
\text { Không có }\end{array}$ & $\begin{array}{l}\text { Có } \\
\text { Có } \\
\text { Có } \\
\text { Không có }\end{array}$ \\
\hline
\end{tabular}

*Khi xuất hiện sớm, phân biệt giữa loại III và IIb có thể khó khăn.

Bảng phân loại này có giá trị định hướng chiến lược điều trị sớm cho bệnh nhân (hình 2).

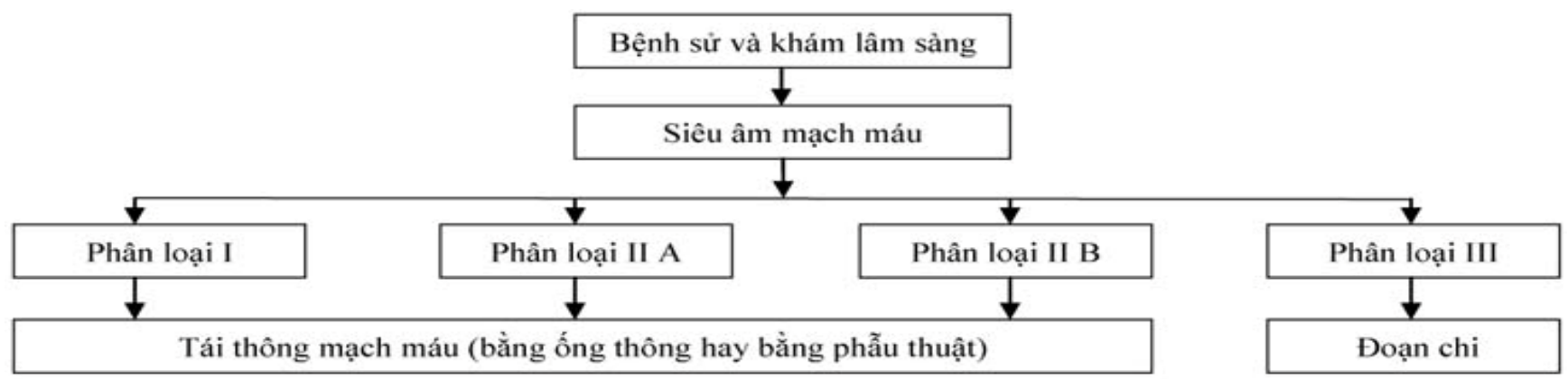

Hinh 2. So đồ tiếp cận bn ALI.

\section{III. Điều trị tiêu sọ̣i huyết động mạch trực tiếp qua ống thông (CDT - Catheter Directed Thrombolysis)}

Trước đây, bn ALI chủ yếu điều trị bằng phẫu thuật lấy huyết khối hoặc làm cầu nối qua chỗ mạch máu bị tắc, tuy nhiên đây cũng là phương pháp điều trị xâm lấn nên nguy cơ phẫu thuật cao và nhiều biến chứng có thể xãy ra. Hiện nay, điều trị tiêu sợi huyết động mạch qua ống thông (CDT) là phương pháp điều trị được lựa chọn đầu tiên dựa trên cơ sở dữ liệu từ các nghiên cứu ngẫu nhiên, tiền cứu ở các bn ALI cho thấy phương pháp điều trị này có hiệu quả tương đương và tỉ lệ tử vong giảm hơn so với phẫu thuật mổ mở, xem bảng 2 . 
Bảng 2. Kết quả so sánh giữa CDT và phẫu thuật [3,4,5].

\begin{tabular}{|l|c|c|c|c|c|c|c|}
\hline \multicolumn{2}{|c|}{} & \multicolumn{2}{|c|}{ Tiêu sợi huyết trực tiếp qua ống thông } & \multicolumn{3}{|c|}{ Tái thông bằng phẫu thuật } \\
\hline Thử nghiệm & $\begin{array}{c}\text { Thời gian } \\
\text { theo dõi }\end{array}$ & Bệnh nhân & $\begin{array}{c}\text { Tái tưới } \\
\text { máu chi (\%) }\end{array}$ & $\begin{array}{c}\text { Tử vong } \\
(\%)\end{array}$ & Bệnh nhân & $\begin{array}{c}\text { Tái tưới máu } \\
\text { chi }(\%)\end{array}$ & $\begin{array}{c}\text { Tử vong } \\
(\%)\end{array}$ \\
\hline Rochester & 12 tháng & 57 & 82 & 16 & 57 & 82 & 42 \\
STILE & 6 tháng & 246 & 88.2 & 6.5 & 141 & 89.4 & 8.5 \\
TOPAS & 12 tháng & 144 & 82.7 & 13.3 & 54 & 81.1 & 15.7 \\
\hline
\end{tabular}

Ngoài ra, CDT còn cho phép:

- Bộc lộ sang thương rõ hơn sau khi làm tan huyết khối.

- Chuyển mức độ can thiệp cấp cứu sang can thiệp bán khẩn hay chương trình.

- Cho thấy thêm sang thương ở hạ lưu.

\subsection{Chỉ định và lựa chọn bệnh nhân}

Dựa vào phân loại $A L I$, các bn thuộc nhóm I và IIa có chỉ định điều trị CDT [2]. Mặc dù các bn nhóm IIb và III khó phân biệt trong giai đoạn sớm và thuộc nhóm chỉ định phẫu thuật, nhưng với chức năng tái tưới máu tạm thời bằng ống thông, chúng tôi nghĩ rằng có thể vẫn ứng dụng được điều trị CDT cho các bn nhóm IIb.

Ngoài ra, việc lựa chọn phương pháp điều trị này còn tùy thuộc vào

- Vị trí giải phẫu của huyết khối.

- Thời gian tắc do huyết khối.

- Nguy cơ xuất huyết phải được cân nhắc với lợi ích điều trị.

- Nguy cơ thủ thuật và nguy cơ bệnh nhân (bệnh lý kèm theo).

Đối với các trường hợp đến trễ hơn 14 ngày, CDT vẫn có thể thực hiện được nhưng hiệu quả điều trị kém hơn. Kết quả các nghiên cứu trước đây cho thấy tỉ lệ sống còn và tái thông lâu dài được cải thiện tốt hơn so với phẫu thuật ở các bn đến sớm 14 ngày, tuy nhiên tiên lượng này xấu hơn khi bn được điều trị CDT trễ hơn 14 ngày [4].

\subsection{Chống chỉ định}

Tương tự như chống chỉ định sử dụng tiêu sợi huyết nói chung được hướng dẫn từ 1980 bởi NIH (National Institutes of Health) [6]:

Chống chỉ định tuyệt đối

- Đang có bệnh lý xuất huyết

- Xuất huyết trong não

○ Hội chứng chèn ép khoang tiến triển
Chống chỉ định tương đối

○ Tiền căn hồi sinh tim phổi 10 ngày trước

○ Tiền căn chấn thương hay phẫu thuật ngoài mạch máu 10 ngày qua

- Tăng huyết áp chưa được kiểm soát : huyết áp tâm thu $>180 \mathrm{mmHg}$ hay huyết áp tâm trương $>110 \mathrm{mmHg}$

○ Vị trí chọc động mạch không thể đè ép được

- U não

○ Phẫu thuật mắt gần đây

- Tiền căn phẫu thuật thần kinh 3 tháng trước

- Chấn thương nội sọ trong thời gian 3 tháng

- Tiền căn xuất huyết tiêu hóa 10 ngày trước

- Tai biến mạch máu não (bao gồm cả cơn thiếu máu não thoáng qua) trong khoảng thời gian 2 tháng

○ Tiền căn xuất huyết nội gần đây

- Suy gan, đặc biệt có rối loạn đông máu

- Viêm nội tâm mạc nhiễm khuẩn

- Có thai và ngay sau sinh

- Bệnh lý võng mạc xuất huyết do đái tháo đường

- Kéo dài cuộc sống < 1 năm

Chọn lựa và liều lượng sử dụng của các thuốc tiêu sợi huyết

Hiện tại, Hội Đồng Dược Hoa Kỳ cho phép sử dụng Alteplase (tPA), Reteplase (RPA), Urokinase (UK), và Tenecteplase (TNK) trong điều trị CDT. 
Streptokinase không được đề nghị vì hiệu quả kém so với các thuốc trên. Một phân tích hồi cứu không ngẫu nhiên gần đây cho thấy các thuốc tiêu sợi huyết thế hệ sau streptokinase có hiệu quả điều trị tốt hơn nhiều (xem bảng 3) [7].

Bảng 3. Kết quả so sánh hiệu quả giữa streptokinase với Urokinase và Alteplase

\begin{tabular}{|l|c|c|c|}
\hline & Streptokinase (\%) & Urokinase (\%) & Alteplase (\%) \\
\hline Ly giải huyết khối hoàn toàn & 60 & 91 & 95 \\
Biến chứng xuất huyết nặng & 48 & 12 & 6 \\
Tử vong & 4 & 2 & 0 \\
Xuất huyết não & 2 & 0 & 2 \\
\hline
\end{tabular}

\subsection{Liều điều trị của tiêu sọii huyết qua ống thông(Catheter Dicrected Thrombolysis - CDT)}

Liều điều trị của các thuốc tiêu sợi huyết theo CDT thường là liều thấp hơn nhiều so với cách dùng truyền thống qua tĩnh mạch trong điều trị nhồi máu cơ tim cấp. Tuy nhiên, hiệu quả của các phác đồ trong các thử nghiệm trước đây đã được chứng minh và được thống nhất đề nghị theo hướng dẫn của Hội Can Thiệp X-quang Châu âu. Liều lượng của các thuốc tiêu sợi huyết được tóm tắt trong bảng 4.

Bảng 4. Liều dùng các thuốc tiêu sọii huyết theo phương pháp CDT.

\begin{tabular}{|l|l|}
\hline Thuốc tiêu sợi huyết & Phác đồ \\
\hline Urokinase & $240.000 \mathrm{UI} /$ giờ/4 giờ đầu; $120.000 \mathrm{UI} /$ giờ sau đó tối đa 48 giờ. \\
Alteplase & $0.12-2.0 \mathrm{mg} / \mathrm{giờ} / 24$ giờ, liều tối đa không quá 40mg. \\
Reteplase & $0.25-1.0 \mathrm{UI} / \mathrm{giờ} / 24$ giờ, liều tối đa 20 UI. \\
\hline
\end{tabular}

Đối với bệnh nhân này chúng tôi sử dụng Urokinase 240.000 UI/giờ trong 4 giờ đầu, sau đó là 120.000UI/giờ trong 20 giờ còn lại, sau 24 giờ chúng tôi rút ống thông khám lại thấy cẳng bàn chân phải ấm, vận động và cảm giác bình thường, siêu âm có phổ Doppler động mạch chày trước và động mạch mác. Sau 48 giờ chụp MSCT mạch máu kiểm tra thấy động mạch đùi nông - khoeo - chày trước và động mạch mác phải bắt thuốc tốt, động mạch chày sau tắc hoàn toàn do vôi hóa nặng.

\subsection{Kỹ thuật CDT}
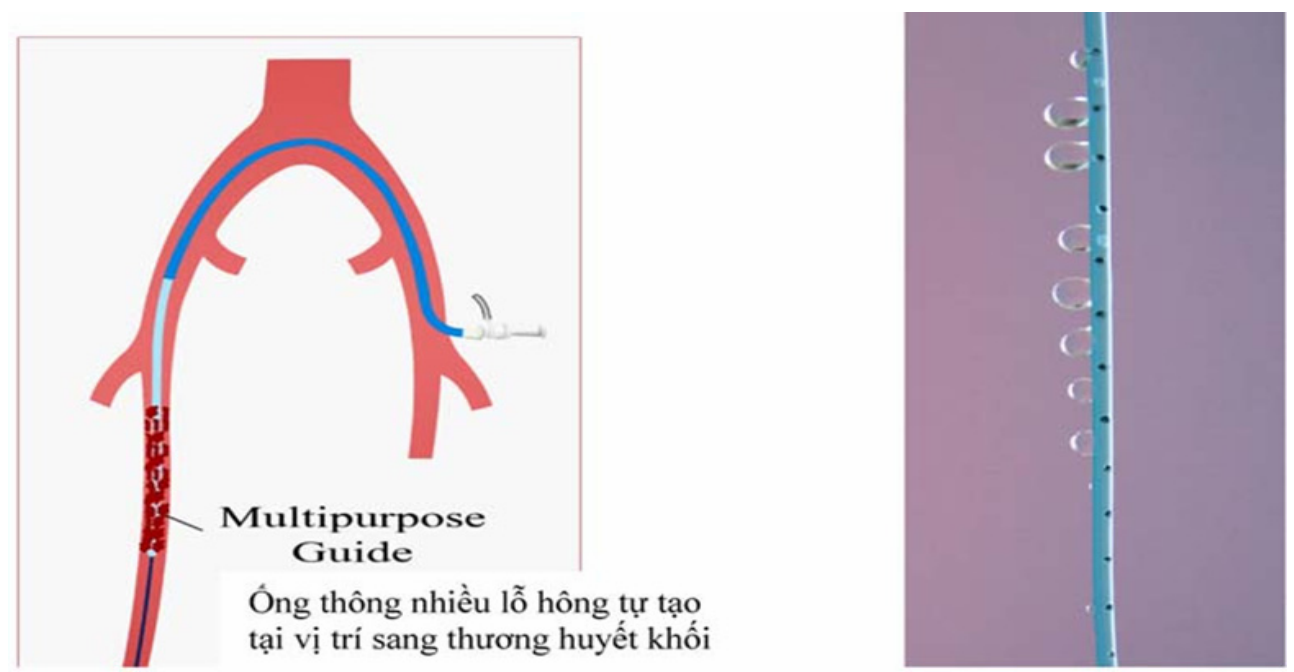

Hình 3. Ống thông nhiều lỗ hông đặt tại vị trí sang thương có huyết khối. 
Kỹ thuật này đầu tiên được Dotter báo cáo vào năm 1974, sử dụng streptokinase truyền qua ống thông trong động mạch để điều trị các trường hợp tắc động mạch và tắc cầu nối [8]. Kể từ đó, kỹ thuật được phát triển với sử dụng các thuốc tiêu sợi huyết chọn lọc hơn cũng như kết hợp với các kỹ thuật hút huyết khối cơ học.

Kết quả các thử nghiệm ngẫu nhiên đã cho thấy cải thiện tỉ lệ sống còn và lợi ích lâu dài do với phẫu thuật cũng như giảm được tần xuất phẫu thuật đối với các bệnh nhân ALI (< 14 ngày) [3,4,5]. Dựa trên cơ sở này, Hội Can Thiệp X-Quang Châu âu đã đưa ra hướng dẫn điều trị ALI bằng phương pháp này và khuyến cáo nên chọn lựa đầu tiên.

\section{Biến chứng CDT:}

- Xuất huyết não - màng não: tri giác lơ mơ hoặc hôn mê

- Xuất huyết đường tiêu hóa: BN ói ra máu, tiêu phân đen

- Xuất huyết đường niệu: tiểu ra máu

- Ngoài ra còn có xuất huyết dưới da hay tại chỗ đặt ống thông nhiều lỗ

- Biến chứng tắc mạch: Có thể tắc mạch não hoặc mạch chi do huyết khối từ nơi khác đến

\subsection{Trắc nghiệm Traversal}

Đây là phương pháp xác định khả năng thành công của CDT. Trắc nghiệm này được McNamara và Fischer [9] thực hiện bằng cách luồn guidewire qua huyết khối dễ dàng hay không, nếu qua dễ dàng khả năng điều trị thành công với CDT rất cao $(100 \%$ so với $10 \%$, $\mathrm{p}=0.003$ ). Tuy nhiên, trắc nghiệm thất bại không phải là chống chỉ định của CDT, nhưng dự đoán kết quả thành công thấp hơn. Trong quá trình điều trị CDT, cần theo dõi các vị trí dễ xuất huyết (đặc biệt vị trí làm thủ thuật) chức năng đông máu, huyết sắc tố và fibrinogen. Giá trị fibrinogen $<100 \mathrm{mg} \%$ đi kèm với tần xuất chảy máu nặng gia tăng $[4,10,11]$.

\subsection{Sử dụng heparin trong thò̀i gian điều trị CDT}

Nhằm phòng ngừa huyết khối xuất hiện quanh ống thông, heparin truyền tĩnh mạch được sử dụng cùng lúc, nhưng liều lượng trong các nghiên cứu khác nhau nhiều, tuy nhiên tỉ lệ xuất huyết não khoảng 4.8\%. Sau này, khuyến cáo sử dụng liều thấp dưới ngưỡng điều trị đích và khuyến khích sử dụng qua đường động mạch nhằm giảm tỉ lệ xuất huyết. Trong các nghiên cứu liều heparin thay đổi nhiều, 100-1000 UI/giờ và được chỉnh liều theo ACT. Chúng tôi sử dụng liều heparin khoảng 200 - 400 UI/giờ, theo dõi chức năng đông máu mỗi 6 giờ thấy khá ổn định với giá trị chỉ đạt gần ngưỡng điều trị.

Trong trường hợp thứ nhất, bệnh nhân tắc động mạch chi cấp tính được xếp loại IIb. Trên CTA ghi nhận tắc động mạch đoạn đầu đùi nông mạn tính và hình thành huyết khối từ đoạn cuối động mạch đùi nông đến động mạch khoeo phải dưới gối, do đó phải can thiệp bằng cách nong và đặt stent động mạch đùi nông trước. Sau đó, chụp kiểm tra ghi nhận có nhiều huyết khối ở đoạn cuối động mạch đùi nông và toàn bộ động mạch khoeo, chúng tôi đặt ống thông có chiều dài lỗ thông $20 \mathrm{~cm}$ từ đoạn cuối động mạch đùi nông đến đoạn đầu động mạch chày trước. Qua ống thông chúng tôi sử dụng Urokinase với liều như trên, đồng thời chúng tôi vẫn duy trì Heparin qua long sheath $6 \mathrm{~F}$ để phòng ngừa hình thành huyết khối. Với sự kết hợp đồng thời thuốc tiêu sợi huyết kết hợp đặt stent một thì duy nhất này, chúng tôi không cần phẫu thuật cũng như can thiệp bổ sung lần sau, từ đó tránh được những nguy cơ và biến chứng, nên bệnh nhân an toàn và hiệu quả hơn. Kết quả sau can thiệp rất tốt, theo dõi sau 03 tháng bệnh nhân đi lại bình thường, mạch chày trước bắt được, CTA động mạch khoeo - chày trước và động mạch mác phải bắt thuốc cản quang tốt.

Trường hợp thứ hai, bệnh nhân tắc động mạch chân trái cấp tính ngày thứ 10 được xếp loại IIa, CTA có hình ảnh cắt cụt ở $1 / 3$ giữa động mạch đùi nông cho đến cuối động mạch khoeo trái, chúng tôi đi fountain catheter $4 \mathrm{~F}$ qua sheath $6 \mathrm{~F}$ từ động mạch đùi chung đến cuối động mạch khoeo trái và sử dụng Urokinase theo phát đồ như trên cho kết quả tuyệt vời.

IV. KẾT LUÂAN: Điều trị tắc động mạch chi cấp tính bằng thuốc tiêu sợi huyết động mạch trực tiếp qua ống thông là phương pháp điều trị không cần phẫu thuật nên an toàn, hiệu quả, ít biến chứng. 


\section{MINH HỌA CA LÂM SÀNG}

\section{Bệnh án 1:}

Bệnh nhân Nguyễn Văn N, sinh 1928 có tiền căn tăng huyết áp và rung nhĩ cơn. Nhập viện 09/11/2016 vì đau và yếu chân phải 4 ngày. Khám lúc nhập viện: bệnh tỉnh táo, mạch 1001/p, HA 160/90mmHg; đau chân phải nhiều, cẳng bàn chân phải tím, lạnh, giảm vận động - cảm giác, động mạch đùi chung phải bắt được, động mạch khoeo - chày trước - sau không bắt được, đau bắp chân phải. CTM: Hct 40\%, BC = 70.000(N=65\%), TQ 13", TCK 38”, Fibrinogen 2g/l. Bệnh nhân được siêu âm Doppler với kết quả tắc hoàn toàn động mạch đùi nông + động mạch khoeo phải do huyết khối trên nên xơ vữa, giảm tưới máu nặng vùng cẳng bàn chân phải, tuần hoàn bàn hệ rất ít sau chỗ tắc. Chụp MSCT dựng hình động mạch 2 chi dưới ghi nhận tắc hoàn toàn động mạch đùi nông và động mạch khoeo dưới gối, động mạch chày trước và động mạch mác bắt thuốc cản quang kém, động mạch chày sau tắc hoàn toàn, toàn bộ hệ thống động mạch chi dưới vôi hóa nặng. Bệnh nhân được can thiệp cấp cứu.

Tường trình can thiệp: Chọc kim và luồn long sheath $6 \mathrm{~F}$ từ đùi trái cross over sang đùi phải chụp động mạch ghi nhận tắc hoàn toàn động mạch đùi nông từ chỗ xuất phát đến động mạch khoeo phải dưới gối, động mạch đùi sâu bắt thuốc cản quang tốt. Đưa Guide wire 0.035 và Rubicon 35 xuống động mạch đùi nông - khoeo - chày trước phải; nong động mạch đùi nông - khoeo bằng bóng $5 \times 150 \mathrm{~mm}$, sau đó đặt stent $6 \times 150 \mathrm{~mm}$ chụp kiểm tra thấy lòng động mạch đùi nông mở rộng và bắt thuốc tốt, động mạch khoeo không bắt thuốc và có dấu hiệu cắt cụt(huyết khối); tiếp tục đưa ống thông có nhiều lỗ(catheter) vào động khoeo đến đoạn đầu động mạch chày trước, bệnh nhân được điều trị thuốc tiêu sơi huyết urokinase trực tiếp tại vị trí huyết khối liên tục trong 24 giờ. Sau đó khám lại thấy cẳng bàn chân phải ấm, vận động cảm giác bình thường, động mạch khoeo bắt được, siêu âm Dopplex động mạch chày trước và mác có phổ tốt động mạch chày sau phổ yếu; chụp MSCT ghi nhận động mạch đùi nông - khoeo - chày trước và mác phải bắt thuốc tốt, động mạch chày sau tắc hoàn toàn.

(xem hình 1).

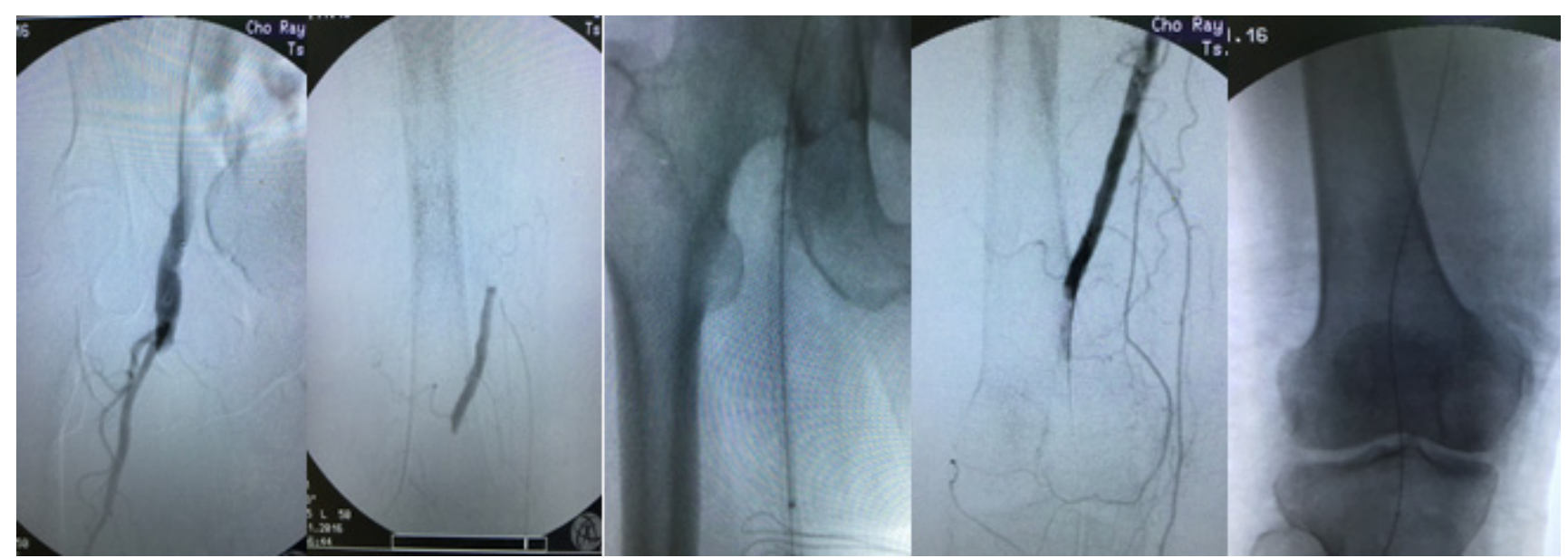

Hinh 1. (A)

(B)

(C)

(D)

(E)

(A), (B): Tắc ĐM đùi nông

(D): Huyết khối ĐM khoeo
(C): Đặt stent ĐM đùi nông

(E): Đặt catheter nhiều lố 


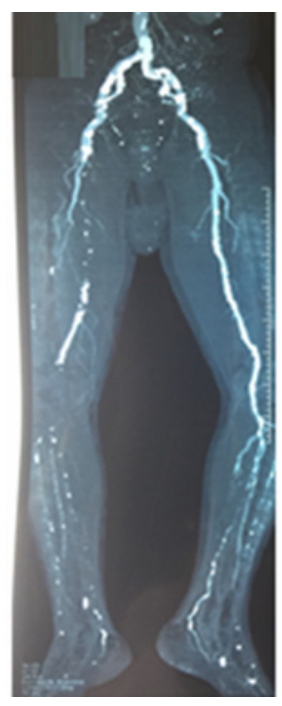

Hinh 2. Trước can thiệp

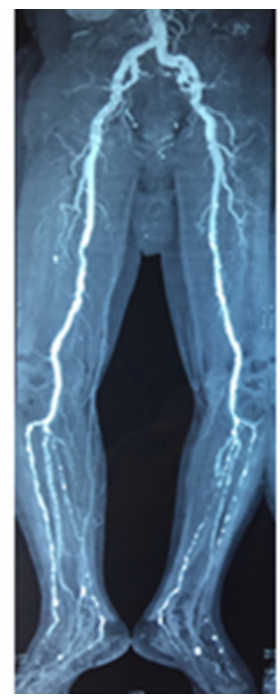

Sau 1 tuần

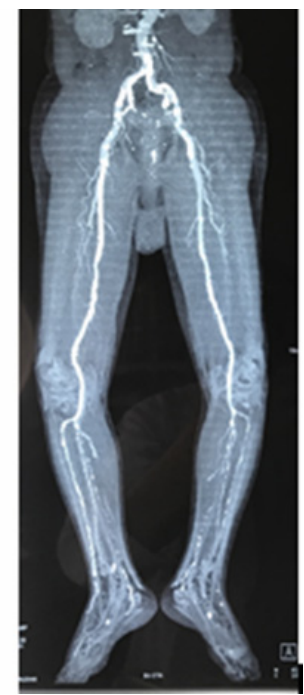

Sau 3 tháng

\section{Bệnh án 2:}

- BN Đặng Văn Ch, sinh 1948, tiền căn tăng HA. Nhập viện vì đau và lạnh chân trái 10 ngày.

- Khám LS: Đau bắp chân trái; cẳng bàn chân tím, lạnh, vận động - cảm giác được; ĐM khoeo chày trước - sau không bắt được.

- Siêu âm Doppler: Tắc ĐM đùi nông $(1 / 2$ dưới $)+$ khoeo + chày trước - sau trái do huyết khối trên nền xơ vữa, giảm tưới máu vùng cẳng bàn chân trái.

- CTA: Tắc ĐM đùi nông + khoeo + chày trước - sau - mác trái, hệ ĐM đóng vôi và xơ vữa.

- CLS: HCT 37,7\%; WBC 9.0G/L; PLT 223G/L; APTT: 38"

- $\mathrm{BN}$ được can thiệp cấp cứu: Chọc kim vào ĐM đùi chung trái chụp kiểm tra thấy ĐM đùi nông + khoeo + chày trước - sau tắc hoàn toàn, ĐM mác còn tái hiện. Luồn catheter fountain 4F qua ĐM đùi nông, ĐM khoeo đến chỗ chia ĐM chày trước - sau, bơm Urokinase 240.000UI, đồng thời sau đó bơm tiêm điện Urokinase 60.000UI/h, liên tục 24 giờ.

- Sau can thiệp: Cẳng bàn chân trái ấm dần, vận động cảm giác bình thường, $\mathrm{BN}$ không biến chứng gì và xuất viện sau 05 ngày.

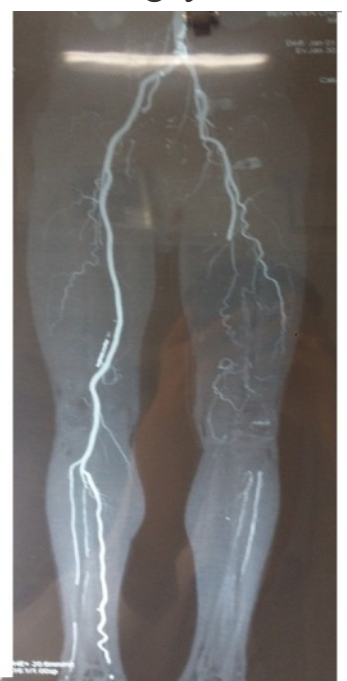

Hìn 3. Trước can thiệp

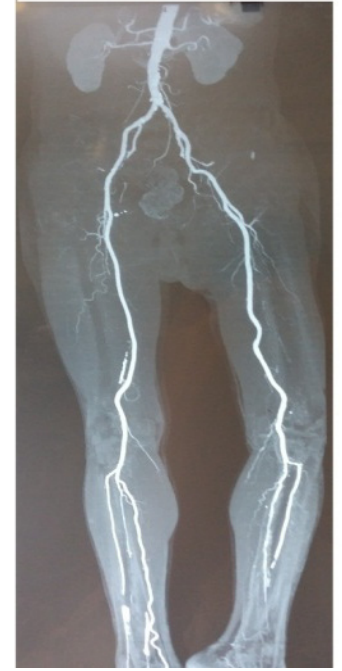

Sau 1 tuần 


\section{TÀI LIỆU THAM KHẢO}

1. Dormandy J, Heeck L, Vig S. Acute limb ischemia. Semin Vasc Surg 1999; 12:148 -153.

2. Dheeraj K. Rajan, MD, FRCPC, Nilesh H. Patel, MD, Karim Valji, MD, John F. Cardella, MD,Daniel B. Brown, MD, Elias N. Brountzos, MD, Timothy W.I. Clark, MD, Clement J. Grassi, MD, MSc,Steven G. Meranze, MD, Donald L. Miller, MD, Calvin D. Neithamer, MD, Kenneth Rholl, MD,Anne Roberts, MD, Marc S. Schwartzberg, MD, Timothy T. Swan, MD, Patricia E. Thorpe, MD, Richard B. Towbin, MD, and David Sacks, MD, for the CIRSE and SIR Standards of Practice Committees. J Vasc Interv Radiol 2009; 20:S208-S218.

3. Ouriel K, Shortell CK, DeWeese JA, et al. A comparison of thrombolytic therapy with operative revascularization in the initial treatment of acute peripheral arterial ischemia. J Vasc Surg. 1994;19:1021-1030.

4. The STILE Trial: results of a prospective randomized trial evaluating Surgery versus Thrombolysis for Ischemia of the Lower Extremity. Ann Surg. 1994;220:251-266.

5. Ouriel K, Veith FJ, Sasahara AA, for the Thrombolysis or Peripheral Arterial Surgery
(TOPAS) investigators. A comparison of recombinant urokinase with vascular surgery as initial treatment for acute arterial occlusion of the legs. $\mathrm{N}$ Engl J Med. 1998;338(16):1105-1111.

6. Thrombolytic therapy in treatment: summary of an NIH Consensus Conference. BMJ 1980; 280(6231):1585-1587.

7. Amonkar SJ, Cleanthis M, Nice C, et al. Outcomes of intra-arterial thrombolysis for acute $\operatorname{limb}$ ischemia. Angiology 2008;58:734-42.

8. Dotter CT, Rosch J, Seaman AJ. Selective clot lysis with low-dose streptokinase. Radiology 1974; 111:31-37.

9. McNamara TO, Fischer JR. Thrombolysis of peripheral arterial and graft occlusions: improved results using highdose urokinase. AJR Am J Roentgenol 1985; 144:769-775.

10. Ouriel K, Kandarpa K, Schuerr DM, Hultquist M, Hodkinson G, Wallin B. Prourokinase versus urokinase for recanalization of peripheral occlusions, safety and efficacy: the PURPOSE trial. J Vasc Interv Radiol 1999; 10: 1083-1091.

11. Hull JE, Hull MK, Urso JA. Reteplase with or without abciximab for peripheral arterial occlusions: efficacy and adverse events. J Vasc Interv Radiol 2004;15:557-564. 